\title{
New clinical guidelines say misconceptions have surrounded hormone therapy
}

$\mathrm{H}$ ormone therapy is a safe, effective short-term treatment for women at the outset of menopause, and doctors should no longer be afraid to prescribe it, say Canada's obstetricians and gynecologists.

The Society of Obstetricians and Gynaecologists of Canada has released new clinical guidelines (JOGC 2009; 31(1Suppl]:S1-52) that seek to reverse the negative image hormone therapy earned after a major US study appeared to link hormones to increased risk of breast cancer, heart attack and stroke (JAMA 2002; 288[3]:321-333).

Dr. Robert Reid, a professor of obstetrics/gynaecology at Queen's University and the lead author of the Journal of Obstetrics and Gynaecology Canada article, said that the Women's Health Initiative study which led to the public misconceptions looked primarily at women in their 60s and 70s.

As well, the media and physicians misinterpreted the statistical risk of breast cancer and cardiovascular disease, Reid told a press conference.

The absolute risk of breast cancer for women who had been taking hormone therapy for 4 years was an additional 8 cases per 10000 women per year. That translates to an increased risk of $0.08 \%$.

"A risk of 1 in 1000 is considered a rare risk - yet nowhere in publishing and reporting did women get that perception," Reid said. Using either combined estrogen and progestin or estrogen alone for less than 5 years "will have little appreciable risk," he added. "That's a message that has been lost to women and their prescribers, who are fearful of prescribing it."

The Women's Health Initiative study was widely reported to have demonstrated an increased risk of heart attack, stroke and breast cancer in women who received hormone replacement therapy to treat hot flashes, night sweats and other vasomotor symptoms of menopause.

Many doctors began advising their patients to stop taking hormone therapy. In North America, an estimated 50\% of patients adopted that advice. The resulting demand for something to relieve symptoms fuelled a "multibillion market for alternative and complementary therapy," Reid said.

But there is little trial evidence in

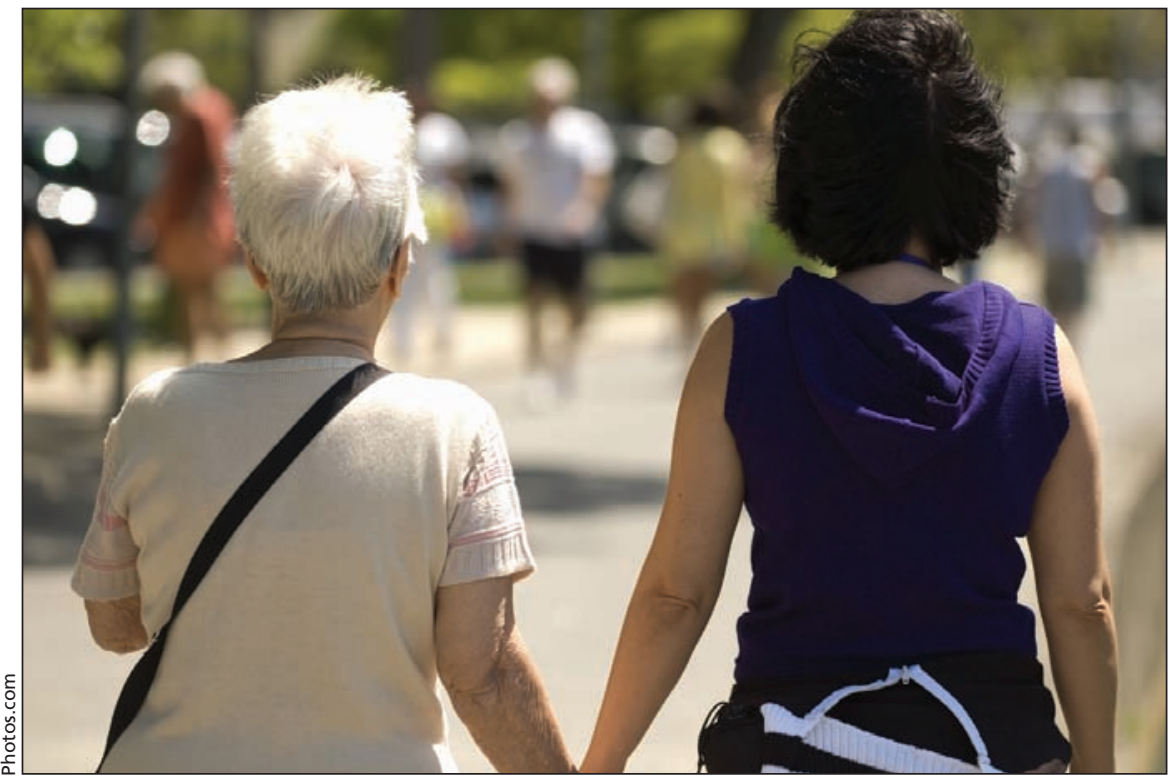

An influential study that linked hormones to increased risk of breast cancer, heart attack and stroke looked primarily at older women, but hormone therapy is safe for women at the outset of menopause, and doctors should no longer be afraid to prescribe it, say Canada's obstetricians and gynecologists.
North America to demonstrate that alternative therapies, such as primrose oil or black cohosh, actually work, said Reid. "No treatment is as effective as hormone therapy."

New analyses since 2002 demonstrates that risk varies depending on the age of patients, and increased cardiovascular risks do not apply to women aged 50-60, the Society said. It also stressed that doctors should not prescribe hormone therapy for the sole purpose of reducing the risk of cardiovascular disease.

But Dr. Salim Yusuf, professor of medicine and director of the Population Health Research Initiative at McMaster University in Hamilton, Ontario, urges doctors to remain cautious and not place too much confidence in subsets of data involving cardiovascular risk that were reinterpreted from the original Women's Health Initiative study.

"Most international experts feel that unless such results are replicated you can't take comfort in it, and you have to depend on the overall results of the trial," he says, adding that more than $50 \%$ of postmenopausal women have increased risk factors for heart disease and stroke.

Adding hormone therapy would increase that risk, Yusuf says. "I would not quarrel with the position to say there is reason for an occasional individual to use it and the risks are modest - but I think the old approach when one was throwing it around like sweeties is not good medicine."

Practitioners should interpret this new advice "with extreme caution" and use hormone replacement therapy sparingly, and for the shortest period possible, for relief of severe symptoms, says Yusuf.

Doctors and patients should also be mindful of the Society's potential conflict of interest, as it takes money from drug companies while recommending hormone therapy, says Barbara Mintzes, assistant professor at the University of British Columbia's Anesthesiology, Pharmacology and Therapeutics Department. Studies in Vancouver, British Co- 
lumbia, have shown "evidence of a link between the advice provided in guidelines and sponsorship of the guidelines or financial links of individual guideline authors as well," she says.

No pharmaceutical companies had any direct involvement in the guidelines, said Reid.

But 5 of the guidelines' 6 authors, including Reid, declared more than 50 conflicts of interest, including being consultants, speakers, advisory board members or receiving research support from such firms as Wyeth Pharmaceuticals, which manufacturers Premarin (conjugated estrogen), one of the leading hormone replacements.
The Society does not believe it is acceptable to tell women just to put up with their symptoms, Reid said, adding that any additional risk of breast cancer disappears after women discontinue hormone therapy. The majority of women who do discontinue therapy after using it for several years will not see their symptoms reappear.

The Society last updated its guidelines in 2006, but more definitive data about cardiovascular risk have since been released, Reid said. Women's Health Initiative investigators said "cardiovascular risk is not an issue for women taking it [hormones] in the first 10 years."
The new guidelines emphasize the importance of modifying lifestyle risks, such as being overweight, smoking, drinking alcohol and not getting enough exercise, as crucial to reduce both cardiovascular and cancer risks.

"A message we need to get out is that it's a safe option to consider... It shouldn't be taken off the table," Reid said.

Several clinical trials are now underway to assess whether there is a cardioprotective effect from hormone therapy started shortly after menopause. Laura Eggertson, CMAJ

DOI:10.1503/cmaj.090164

\section{FOR THE RECORD}

\section{Ethical disclosure}

$\mathrm{T}$ he Association for Medical Ethics has issued guidelines for ethical rules of disclosure recommending that all physicians and scientists "disclose in all publications and presentations the precise nature and amount of any financial conflicting interest exceeding $\$ 500$ per calendar year."

Only through such full disclosure is it possible to determine whether research findings have any measure of independent validity, the association argued.

The new guidelines (www.ethical doctor.org/Ethical_Rules_of_Disclosure .html), also recommend that scientists doing "publishable clinical research should eliminate substantive personal financial interests, if present, prior to engaging in such research. Grants from industry may be directed, but should be unrestricted and departmental."

The guidelines are the latest call for stricter regulation of conflicts of interest in the wake of concerns that industry handouts are increasingly influencing therapeutic decisions and compromising the medical profession's reputation, (CMAJ 2008;178[13]:1651-2 and CMAJ 2008;179[11]:1118). Wayne Kondro, CMAJ

\section{Shoddy production}

I n mid-January, the United States Food and Drug Administration (FDA) announced that the pharmaceutical firm Actavis Inc., which closed one of its plants because of shoddy manufacturing practices, could resume making and selling certain drugs only if it meets "Good Manufacturing Practice" requirements.

Actavis recalled its heart drug Digitek (one brand of digoxin) on Apr. 25, 2008, after it was discovered that some tablets, produced in New Jersey, were twice as thick as

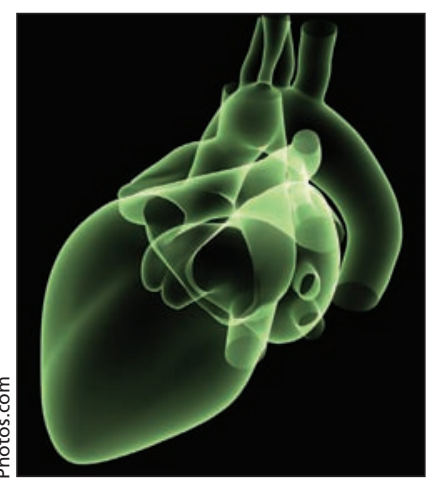
they should have been. This meant, of course, that each tablet contained double the dose of the powerful heart drug, known generically as digoxin. Actavis claims, however, that no incorrectly manufactured pills entered the consumer market.

Yet, according to The Center For Public Integrity, Digitek was cited as the "primary suspect" in 667 deaths reported to the FDA between Apr. 1, 2008, and Jun. 30, 2008.

Digoxin, which is used to treat heart conditions such as atrial fibrillation, atrial flutter and heart failure, has a narrow safety margin. Even a slight dosage increase can prove fatal.

Last August, Actavis closed the New Jersey plant to fix its manufacturing problems. In November, the US Justice Department asked a federal judge to keep the plant closed, at least until the company could prove it met "Good Manufacturing Practice" standards, as set by the FDA.

In late December, Actavis signed a "proposed consent decree" agreeing to this condition. The company might not, however, start making Digitek again, it has been reported.

Actavis Inc., based in Morristown, New Jersey, is a division of the Icelandic Actavis Group, which operates in 40 countries and has 11000 employees. The pharmaceutical company is one of the world's 5 largest drug makers. - Roger Collier, CMAJ 